\title{
Specialties of first SMED in pharmaceutical manufacturing
}

\author{
Á. BENE ${ }^{1}$, P. BENE 2 \\ ${ }^{1}$ University of Debrecen, Faculty of Applied Economics and Rural Developement, beneagi@yahoo.com \\ 2 University of Debrecen, Faculty of Informatics
}

Abstract. Single Minute Exchange of Die (SMED) is considered as an effective lean management method increasingly used in pharmaceutical manufacturing. By reducing change-over times and costs, the successful implementation of the first SMEDs may bring a significant increase in terms of manufacturing flexibility. The purpose of this study is to present the special factors that fundamentally determine SMEDs applied especially in the process of pharmaceutical manufacturing. By focusing on a well defined part of the pharmaceutical manufacturing process, lasting from Weighing and Measuring to the end of Tablet Pressing, the study also aims to highlight the benefits of SMED itself. The findings of the research are based on the practical experiences of four SMEDs implemented in various sections of production. According to the experiences and considering industrial specialties, the implementation of SMED has to harmonise with the requirements of Good Manufacturing Practices (GMP) which are representing the golden quality standards of pharmaceutical manufacturing.

\section{Introduction}

Nowadays, pharmaceutical companies need to increase their production flexibility by producing in smaller batches in order to stay competitive in a global market. Thus, finding ways to reduce internal costs and cycle times has become a key issue to deal with. In the pharmaceutical industry, small batch manufacturing requires the ability of performing quick setup processes and meeting quality standards at the same time. [2;6] Therefore, a healthy mixture of management tools and methods is expected today, in order to design and provide an efficient response to the challenges of tomorrow.

In light of the above, turning to lean management and implementing SMEDs seem to be an obvious path, chosen by pharmaceutical manufacturers, to follow. In particular, the widespread of pharmaceutical lean in Hungary has become a reality when major players of the industry with production capacity in Hungary (Richter, Sanofi, Egis, Teva) have been committed to lean implementation in recent years.

Considering the relevant regulations and quality requirements, this study aims to highlight the special quality standards and practices of GMP which are applied during the implementation of SMEDs in pharmaceutical manufacturing. 
The paper itself is structured in 5 sections. After the introduction, section 2 gives a brief review on lean, GMP and SMED. Section 3 provides the study of SMED implementation and Section 4 presents the main results obtained. Finally, in section 5 the summary of the paper is outlined.

Presenting the balance of power in the marriage between lean (SMED) and GMP, that is what this paper stands for.

\section{LEAN, GMP and SMED in the pharmaceutical industry}

\subsection{Lean}

With the unquestionable contribution of Taiichi Ohno, the concept of lean arose from the Toyota Production System (TPS) which was developed in the 1950s at Toyota, Japan. The term was first used in the 1980s by a research team headed by Jim Womack., at MIT's International Motor Vehicle Program to describe Toyota's business [Internet 2.].

A lean organisation makes an effort to regularly identify and eliminate waste and recognize employee contributions by continuous process improvement, enabling increased flexibility and competitiveness [2; 6]. From the "magic box" of lean management, several tools and methods can be applied by manufacturing companies in order to improve their performance.

\subsection{GMP}

Good Manufacturing Practices (GMP) represent the governing principles for the production, distribution and supply of pharmaceuticals. [1].

The first text on GMP was prepared in 1967 by a group of consultants of the World Health Organisation (WHO) and was accepted by the Twenty-first World Health Assembly under the title Draft requirements for good manufacturing practice in the manufacture and quality control of medicines and pharmaceutical specialties. Considerable developments in GMP have taken place in next decades, and important national and international documents, including new revisions, have appeared [8].

GMP is part of the quality assurance system in the pharmaceutical industry which ensures the medicinal product to be manufactured and controlled according to the requirements prescribed, the facts stated in the Manufacturing Authorisation and to be appropriate for the purpose they have been granted. Any manufacturing process of medicinal products in Hungary (this includes manufacturing and packaging of active substances, manufacturing, batch release and quality control of medicinal products) has to be carried out only in possession of a valid manufacturing license for medicinal products issued by the National Institute of Pharmacy [Internet 1].

The guidelines of GMP provide requirements on quality management systems, personnel, production facilities and equipment systems, materials system, documentation and records, production systems and in-process controls, packaging and labeling systems, storage and distribution, laboratory control systems, validation, complaints and recalls, and contract manufacturers [1]. 
In the pharmaceutical production the main objectives of GMP include prevention of possible contamination and cross-contamination. In the interest of prevention, and detecting possible contamination or cross contamination the prescribed method is sampling. The results of sampling serve as the evident in compliance with standards in cleaning, validation process. For all methods the sampling points must be fixed in a manner that the true contamination of the equipment will be reflected. The used sampling method to be placed on appropriate sampling points in the equipment during the manufacturing of the previous product and during change over procedure with cleaning. Visual test and chemical evaluations of the equipment can be performed after a clean to demonstrate that product residues (active ingredient, intermediates and / or excipients) and cleaning agent residues (solvents, chemicals used in process) have been removed to levels within the acceptance criteria.

\subsection{Lean and GMP, a curious marriage}

Compared to other sectors of manufacturing, the pharmaceutical industry has relatively slowly been adapting lean. A possible reason for this is that, as we have seen, GMP has been representing a complex system of requirements and institutionalized tradition of pharmaceutical manufacturing for decades. Due to the apparent success of lean in general manufacturing, a growing number of players of the pharmaceutical industry have also decided to implement lean so that they can accomplish their strategic goals such as decrease wait time to release a product to the market, reduce production waste, improve communication with patients and increase quality level in production and testing laboratories. Thereby, for pharmaceutical and medical device manufacturers, lean manufacturing represents the way for significant improvement of quality and operational efficiency [6].

The challenge for them in turning to lean is that all new operational procedures must be compliant with the requirements of GMP, and also support continuous improvement. (While lean focuses on continuous improvement and value creation, GMP focuses on ensuring safety, reliability and quality) [6].

Therefore, in pharmaceutical manufacturing, the methods of lean management must be harmonised with the standards of GMP.

\subsection{SMED}

Single minute exchange of die (SMED) is a lean management tool introduced by Shigeo Shingo to reduce setup durations from hours to minutes and eliminate wastes identified in the changeover operations ${ }^{1}$. [2].

Converting a manufacturing process, from running the current product (current lot) to running the next product (next lot), as quickly and effectively as possible, that was the main potential behind this idea. The increasing competition between Toyota and Volkswagen in the 1980s and the publication of

1 Change over time is defined as a method of analyzing and reducing the time needed to change a process from producing one good part to producing the next good part [7]. 
Shingo's famous book on "A Revolution in Manufacturing The SMED System" were just the beginners of SMED's worldwide success. By using SMED, a set of techniques has been becoming accessible for companies, from different areas of production, in order to serve flexibility of respond to demand. [3].

According to Shingo, setup / changeover operations can be divided into two categories: internal operations (can only be performed while the machine is stopped) and external operations (can be performed while the machine is operating) [2].

According to this line of reasoning, the basic model of SMED implementation consists of the following stages:

Preliminary Stage - Internal and external setup are not differentiated;

Stage 1 - Separate internal and external setup;

Stage 2 - Convert internal into external setup;

Stage 3 - Rationalize the internal and external setup/ Streamlining all aspects of the setup operation $[2 ; 7]$

The philosophical background of lean says about SMED reasons: because of long format change, the company is less responsive to the wishes of the customer.

Generally, SMED aims to standardize and simplify the operations, in addition the production can be more plannable. By this means, the need for special skilled workers is also minimized [7].

Before this method, changeover / setup time was considered as a necessary bad thing, in the production, that may be improved a bit at large cost, if possible, but not really avoidable. By reducing change-over times and costs, the successful implementation of the first SMEDs may bring significant improvements in terms of quality and production flexibility.

\section{Study}

The research of this paper was carried out in Hungary, in the solid dosage plant of a global pharmaceutical company.

\subsection{Sample}

For our empirical research we have chosen four "first SMED projects" representing a well defined part of the pharmaceutical manufacturing process, lasting from Weighing and Measuring to the end of Tablet Pressing.

- SMED: Weighing and measuring room with air locks (personal and material)

- SMED: Bohle bolting-room with air locks (personal and material)

- SMED: Glatt 2 /Granulating

- SMED: Fette 2090 /Tableting 


\subsection{Method: SMED Lean workshop}

For the standard application of different lean tools, the method of a Lean workshop was developed at the corporate level. The workshop itself supports problem solving with a well defined combination and number of attendants by root cause analysis ${ }^{2}$ and continuous improvement of performances.

According to the standard, the number of attendants may vary from 7 to 10 persons, and consists of workers from the shop floor, lean expert(s), employees from other related department(s), operators from shop floor. The leader of the workshop is chosen by senior management. The top manager and the members of senior management are also involved through their attendance to the workshop presentations. By working on processes which are directly creating value for the customer, the shop floor worker is considered as the key attendant of the workshop, nevertheless, the results of the workshop will also be implemented by this employee in the main.

\section{SMED training for participants}

Holding a Lean workshop, according to corporate standards, focusing to SMED is appropriate to involve the employees. Having defined the scope of attendants, the venue and time, the Lean department arranges the process of SMED.

Intensive work starts with SMED training for participants on the gemba ${ }^{3}$. According to lean terminology, the gemba can be found where the things happen, most of the occasion on the shop floor.

\section{Gemba observation}

Detailed gathering of data by using the method of observation is an essential part of SMED. Each employee taking part in change-over process is followed by observers. The duties of observers are:

- Activity observing minute by minute (all the activities)

- Drawing Spaghetti charts 4

- Muda ${ }^{5}$ hunting / Note the wastes

- Photo documentation

- Documentation to be used by changeover (collect, score up)

The implementation of first SMED requires a previous analysis of changeover process in order to know the details of each setup operation [2].

Intensive teamwork

\footnotetext{
2 Root cause analysis/ Five whys: The practice of asking „why” repeatedly (five times) whenever a problem is encountered in order to get beyond the obvious symptoms to discover the root cause [4].

3 Gemba: Japanese term, „actual place” used for the shop floor, and any place where value-creating work actually occurs [4].

4 Spaghetti chart shows the movements of observed person. Drown lines can be looks like a plate of spaghetti.

5 Muda: Muda means waste. Seven wastes are: overproduction, waiting, transportation (or conveyance), processing, inventory, motion, defect (or correction).
} 
Intensive teamwork is performed in a room especially dedicated for this purpose, ensuring appropriate working conditions for the team. Every single operator of the observed changeover process are attending among team members. They are the most important participants of teamwork, as their suggestions are based upon real practical experiences, and the actions will also be implemented by these operators in the main. Additional members of the team: lean facilitator, department leader (leader of the organisational unit), shift leader of another department (unit), colleague from the quality assurance (QA) department. The compliance with the health, safety and environment (HSE) principles / standards was ensured by the shift leaders who are acting as qualified HSE representatives in their departments.

The implementation process of SMED was divided into seven stages as follows:

1) Analyze the changeover time

a) Analyze all actions performed during the format change, from the second the machine stops until it's restarted with a good quality production.

2) Divide the changeover time into internal and external actions

b) Internal actions: All necessary changeover operations which have to be made with the machine shutdown.

c)

d) External actions: All changeover operations doable while the machine is still running.

3) Transfer tasks from internal to external

e) At this step the goal is transferring tasks, which are made before or after stopping from internal to external, without touching (yet) the total change duration to reduce the machine downtime.

4) Optimize the internal phase of tool change (use parallelization)

5) Optimize the external phase of tool change (use parallelization)

6) Build up Action plans

7) Finalization, quick implementation

At the end of the Workshop all the results were presented to management and guest employees, involved each participants of intensive team work.

\section{Results}

After the first observations the following key points were registered by the team, as a basis for improvement:

- long changeover times

- unnecessary / long / repeated movements are made by the operator and material handler

- lack of space in the shop floor

- disorganisation of equipment (during the change over)

- versatility in cleaning methods among the areas (used chemicals, tools) 
- versatility in contact times of using chemicals

For solving these problems effectively, the team decided to support SMED with the tools of activity cards (with parallelization), new standards, tool kits (with photo illustration), kanban card (Weighing and measuring area), 5S (different places).

Activity card: This standardised form provides details participants on change over procedure. All the activities according to SMED future state are enumerated with time frames for each participants (operator1,operator2, material handler).

Tool kit: A kit composed upon the exact definition of the tools needed for a changeover. Check list, photo may help in the process of standardizing. Tool kits may also be put for supporting construction work and cleaning, as maintenance tool kit and cleaning tool kit.

Kanban card: The term comes from Japanese "sign" or "signboard". Kanban is a signaling device that gives authorization and instructions for the production or withdrawal of items in a pull system [4]. Kanban card is a visual signal, which can be possible bright colourful with short instruction on it.

5S: Five related terms, beginning with an S sound, describing workplace practices conducive to visual control and lean production [4]. The five terms in Japanese are: Seiri: Separate needed and unneeded items.; Seiton: Organisation of needed items (place for everything and everything in its place).; Seiso: Clean and wash.; Seiketsu: Cleanliness, standardization, and training for employees.; Shitsuke: Following the standards, and continuous improvement.

The 5S are often translated into English as Sort, Straighten, Shine, Standardize, and Sustain. A possible sixth S can be for Safety: Establish and practice safety procedures in the shop floor and office [4].

Based on the currant state Gantt charts, after the evaluation of gemba observation and documents, future state Gantt charts created.

Figure 1. shows demand of time by the new processes developed.

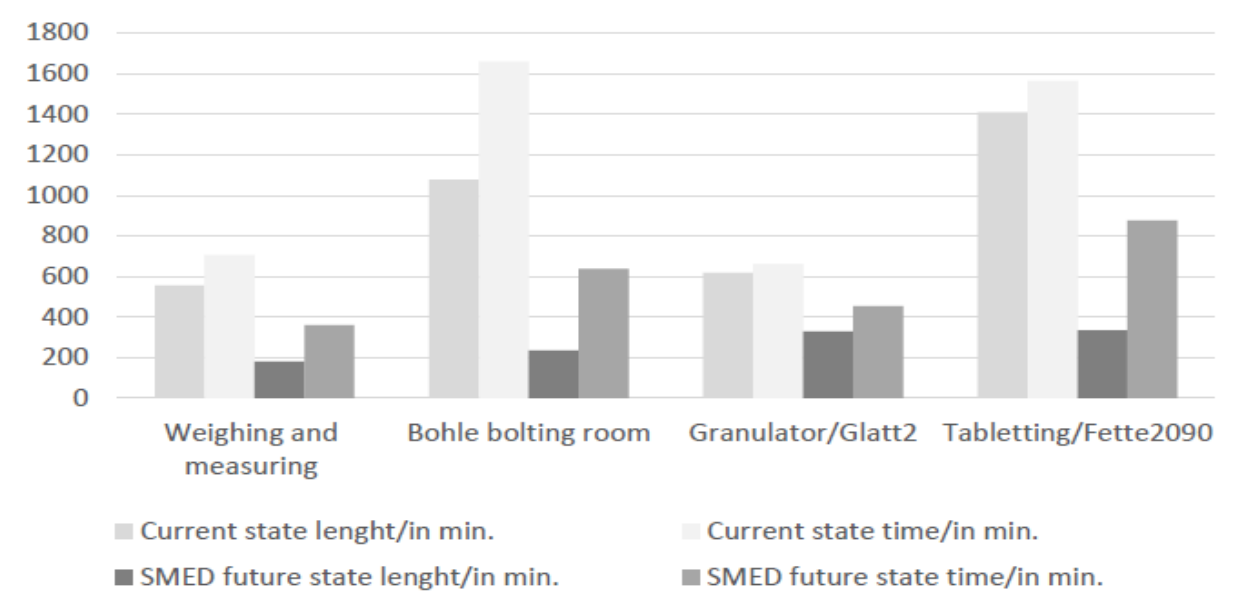

1. Figure, SMED times 
Owing to the first SMEDs, a dramatic reduction of changeover times was achieved in all the four areas observed. By the used of the activity cards developed, and the implementation of actions, the keeping of the defined time frames can be ensured.

With building up change over procedures with paralleled activities Table 1.shows the demand of human resources by the new processes developed.

\begin{tabular}{|c|c|c|c|c|}
\hline & \multicolumn{2}{|c|}{ Current state } & \multicolumn{2}{|c|}{ SMED future state } \\
\hline & operator & $\begin{array}{l}\text { material handler } \\
\text { /container cleaner* }\end{array}$ & operator & $\begin{array}{l}\text { material handler } \\
\text { /container cleaner* }\end{array}$ \\
\hline Weighing and measuring & 1 & 0,2 & 2 & 0 \\
\hline Bohle bolting room & 1 & $1 *$ & 2 & $0,5^{*}$ \\
\hline Granulator/Glatt2 & 1 & 0,1 & 1,5 & 0 \\
\hline Tabletting/Fette2090 & 1 & $0,2^{*}$ & 2 & $0,5^{*}$ \\
\hline
\end{tabular}

1. Table, Change over participants

\section{Action plans}

Action plans were defined in order to implement the future state of the changeover process. The actions were put together into the categories according to the corporate standard, as follows: organisation, method and equipment. A clear deadline and a person in charge were dedicated to every action. Action plans with regards to different areas are put together in Table 2.

\begin{tabular}{|l|l|l|l|l|}
\hline & Organisation & Method & Equipment & Total \\
\hline Weighing and measuring & 17 & 9 & 3 & 29 \\
\hline Bohle bolting room & 10 & 9 & 7 & 26 \\
\hline Granulator/Glatt2 & 6 & 6 & 10 & 22 \\
\hline Tableting/Fette2090 & 7 & 10 & 13 & 30 \\
\hline & & & & 107 \\
\hline
\end{tabular}

2. Table, SMED Action plans

The actions of the 1 week long quick implementation and the middle term (max. 3 months) actions like preparing activity cards, representing 29\% (31 pieces) of total action plans, are linked to the implementation of Lean methods.

Further 44\% (47 pieces) of total action plans, among which 25 pieces are with the purpose of sourcing assets and the rest 22 pieces are regarding maintenance and repair, are requiring some kind of technical or technological intervention. 
In the package, the remaining long term (more than 3 months) actions were standing with the need for more complex solutions, and for the deep involvement of QA. These actions are representing $27 \%$ of total action plans, and are here for a further study on their implementation hereinafter.

\subsection{GMP effects on actions}

According to the requirements of GMP, production operations must follow clearly defined procedures in accordance with manufacturing and marketing authorizations, with the objective of obtaining products of the requisite quality [6].

In light of the above, $27 \%$ of the prepared actions for the first SMEDs of the 4 areas are requiring complex solutions. These are the changes, like simplification, reduction, new method, documentation. which are directly reciprocate affecting on GMP. Therefore, further works, discussions and planning are still to be carried out in order to realise the implementation of SMED actions in harmonisation with GMP. The well defined process could be as fallows:

\section{1) Consultation with $Q A$}

Discussion on existing cleaning, validation protocols is needed. Also an important aspect in creating new methods is harmonisation among the areas with calculation contact times and effectivity of chemicals.

The experiences of other production plants gathered from attendants and corporate lean SMED database.

2) Testing (according to "future state")

3) QC laboratory sampling-examinations

Quality Control (QC) is the part of GMP concerned with sampling, specifications and testing, and with the organisation and documentation which ensure that the necessary and relevant tests are actually carried out and that materials are not released for use, nor products released for sale or supply, until their quality has been judged to be compliant with the requirements. The independence of QC from production is considered fundamental. The QC function should be independent of other departments and under the authority of a person with appropriate qualifications and experience[6].

The objectives of GMP include prevention of possible contamination and cross-contamination Prevention of cross-contamination and bacterial contamination during production. Contamination of a starting material or of a product by another material or product must be avoided.

4) Implementation can be realised after evaluation of results.

The evaluation of the experiences may be followed by further consultation. And finally, further SMEDs can also be applied after the success of the first one.

\section{Summary}


Short setup times are a necessity nowadays in all types of industries. The successful implementation of the first SMEDs may bring spectacular results. By the improvement of relevant processes it is possible to reduce changeover times. Innovative improvements take place through the execution of action plans. Communication between departments can be improved as the result of the teamwork.

The specialties of first SMED in pharmaceutical industry can be linked to the strict regulations and requirements of GMP. The challenge for pharmaceutical manufacturers is that the implementation of the results of SMED has to harmonise with the requirements of Good Manufacturing Practices (GMP) and Health, Safety and Environment (HSE). Presenting the balance of power in the marriage between lean (SMED) and GMP, that is what this paper stood for.

The first SMEDs are followed by the implementation. Experiences show that there is a need for further development of changeovers. Such a development may come by the creation of packs of activity cards depending on the manpower available.

SMEDs could be and should be combined with other lean tools, like TPM6, 5S, kanban, supermarket7 . After all, well communicated SMED processes, and results are able to open the door to implement other lean tools.

\section{References}

[1] P. Brhlikova, I. Harper, A. Pollock (2007), Good Manufacturing Practice in the pharmaceutical industry, working paper 3, prepared for Workshop on Tracing Pharmaceuticals in South Asia, July 2-3 2007. University of Edinburgh. letöltés: 2016.03.10. web: http://www.csas.ed.ac.uk/_data/assets/pdf_file/0011/38828/GMPinPharmaIndustry.pdf

[2] E. Costa, R. Sousa, S. Braganca, A. Alves (2013), An industrial application of the SMED methodology and other lean production tools, 4 th. International Conference on Integrity, Reliability and Failure, June 23-27. Funchal

[3] Y. Dave, N. Sohani (2012), Single Minute Exchange of Dies: Literature Review, International Journal of Lean Thinking, Volume 3, Issue 2 , p. 28-37.

[4] C. Marchwinski, J. Shook, A. Schroeder (2008), Lean lexicon: A graphical glossary for Lean Thinkers, The Lean Enterprise Institute, 4th.edition, Cambridge, MA, USA

[5] D. O'Rourke, A. Greene (2006), Lean Manufacturing practice is a cGMP environment, Pharmaceutical Technology Europe, Vol.:18, Issue:10. Oct. 1., 2006. p. 1-5.

[6] K. Pavlovic, V. Bozanic (2010), Lean and Six Sigma Concepts-Application in Pharmaceutical Industry, 4tf. International Quality Conference May 19 th., Kragujevac

\footnotetext{
6 TPM: Total Productive Maintenance The approach is termed total in three senses. First, it requires the total participation of all employees, not only maintenance personnel. Second, it seeks total productivity of equipment by focusing on wastes that plague equipment: downtime, changeover time, minor stops, speed losses, scrap, rework. Third, it addresses the total life cycle of equipment [4]

7 Supermarket: The location where a predetermined standard inventory is kept to supply downstream processes. Supermarkets ordinarily are located near the supplying process to help that process see customer usage and requirements. Each item has a specific location, as an item is removed, a signal to make more (such as a kanban card or an empty bin) is taken by appointee to the supplying process [4].
} 
[7] B. Ulutas (2011), An application of SMED Methodology, International Journal of Mechanical, Aerospace, Industrial, Mechatronic and Manufacturing Engineering Vol:5, No:7, 2011. p. 11941197.

[8] WHO Expert Committee on Specifications for Pharmaceutical Preparations 48th report in WHO Technical Report Series No. 986, Annex 2. 2014. letöltés: 2016.03.09. web: http://apps.who.int/medicinedocs/documents/s21464en/s21464en.pdf

[9] Internet 1. www.ogyei.gov.hu/drug_manufacturing_en/

[10] Internet 2. www.lean.org 